\title{
Anabases
}

ANABASES Traditions et réceptions de l'Antiquité

\section{Pierre RICHÉ et Jacques VERGER, Des nains sur des épaules de géants. Maîtres et élèves au Moyen Âge}

\section{Florence Bouchet}

\section{(2)enEdition}

\section{Journals}

Édition électronique

URL : http://journals.openedition.org/anabases/3245

DOI : $10.4000 /$ anabases.3245

ISSN : 2256-9421

\section{Éditeur}

E.R.A.S.M.E.

\section{Édition imprimée}

Date de publication : 1 mars 2007

Pagination : 271-272

ISSN : 1774-4296

\section{Référence électronique}

Florence Bouchet, «Pierre riché et Jacques Verger, Des nains sur des épaules de géants. Maîtres et élèves au Moyen Âge », Anabases [En ligne], 5 | 2007, mis en ligne le 01 décembre 2011, consulté le 22 septembre 2020. URL : http://journals.openedition.org/anabases/3245 ; DOI : https://doi.org/ 10.4000/anabases.3245

Ce document a été généré automatiquement le 22 septembre 2020

(c) Anabases 


\title{
Pierre RICHÉ et Jacques VERGER, Des nains sur des épaules de géants. Maîtres et élèves au Moyen Âge
}

\author{
Florence Bouchet
}

\section{RÉFÉRENCE}

Pierre RICHÉ et Jacques VERGER, Des nains sur des épaules de géants. Maitres et élèves au Moyen Âge, Paris, Tallandier, 2006, 352 p.+ illustrations

25 euros / ISBN 2-84734-256-7.

1 Les géants, ce sont les sages de l'Antiquité gréco-latine, dont l'héritage profite tant, aux dires de Bernard de Chartres, aux médiévaux. Pour brosser un tableau d'ensemble de cette translatio studii de l'Antiquité au Moyen Âge, deux spécialistes de la culture médiévale se sont associés. $\mathrm{P}$. Riché a rédigé la première partie : "Le temps des écoles ( $\mathrm{VI}^{\mathrm{e}}$-XII ${ }^{\mathrm{e}}$ siècle) "; la deuxième partie: "Le temps des universités ( $\mathrm{XIII}^{\mathrm{e}}-\mathrm{XV}^{\mathrm{e}}$ siècle)" est due à J. Verger.

De fait, les passages de relais féconds des auctores classiques aux clercs n'ont pas manqué durant cette histoire millénaire, unifiée par le constant usage du latin en tant que langue de savoir et d'étude. Les monastères du haut Moyen Âge ont préservé une partie appréciable des textes antiques après l'effondrement de l'Empire romain d'Occident - legs néanmoins subordonné à l'étude du texte sacré, au prix de plusieurs impasses! L'époque carolingienne connaît trois renaissances sous les règnes de Charlemagne (768-814), de Louis le Pieux (814-840) et de Charles le Chauve (843-877) : renouveau des études, extension du réseau des écoles, multiplication des florilèges collectant des extraits d'auteurs classiques (ainsi qualifiés parce qu'ils sont enseignés dans les classes). Le bouillonnement intellectuel du XII siècle occasionne une nouvelle renaissance (écoles de Chartres et de Paris); les traducteurs (de Tolède notamment) rendent accessibles aux litterati occidentaux l'Organon d'Aristote et divers écrits 
scientifiques qui avaient transité par l'Orient arabe et grec. L'ars dictaminis, enseignement de la poésie, s'appuie sur les auteurs anciens (école d'Orléans). La première génération de romans, écrits à partir de 1150, s'inspire d'ailleurs de l'Antiquité. Le goût de l'antique se manifeste aussi par des fouilles (et le pillage des monuments...) Avec l'essor des universités au XIII siècle, la rénovation des arts libéraux fait passer de la logica vetus à la logica nova : l'aristotélisme (dont le succès est redevable aux commentaires d'Avicenne et surtout d'Averroès et d'Albert le Grand) prend le pas sur l'idéalisme platonicien. Ce qui n'est pas sans poser le problème de la compatibilité entre le christianisme (dans la perspective augustinienne) et la pensée matérialiste du philosophe païen; d'où la controverse autour de Thomas d'Aquin cherchant à concilier nature, raison et foi, et de l'averroïsme des maitres parisiens. De tels débats occuperont les universitaires jusqu'à la fin du Moyen Âge, au risque de la sclérose scolastique. Cependant certaines universités (particulièrement en Italie mais aussi à Paris) s'ouvrent à l'humanisme avec de nouveaux cours de rhétorique et même de grec. Au $\mathrm{XV}^{\mathrm{e}}$ siècle, en marge des universités, s'ouvrent (là encore d'abord en Italie) les premières écoles humanistes où la lecture des classiques, de moyen qu'elle était souvent, devient une fin. Rappelons enfin, quoique cela excède l'objet de ce livre, les nombreuses traductions (cette fois en français) de grands classiques réalisées sous l'impulsion royale (Jean II, Charles V) ou princière (Jean de Berry). Ainsi les médiévaux ont-ils, au fil des siècles, inventé, à l'aune des Anciens imités, commentés, réinterprétés, leur propre modernité, ferment culturel pour l'Europe à venir.

3 L'ouvrage, composé de dix-sept courts chapitres, a les vertus pédagogiques requises par son sujet, mais l'on peut regretter que le souci de clarté lié au travail de vulgarisation cantonne par endroits l'exposé dans l'énumération descriptive. Les auteurs adoptant un point de vue surtout social et institutionnel, il faudra, pour connaître plus en détail le contenu intellectuel de l'enseignement médiéval, se reporter à certains des ouvrages signalés dans la bibliographie. En somme, une synthèse utile à tous ceux qu'intéresse l'histoire des idées et de l'éducation, point de départ d'autres lectures.

\section{AUTEURS}

\section{FLORENCE BOUCHET}

Université de Toulouse II-Le Mirail

flo.bouchet@libertysurf.fr 